\title{
Research on the Disposition Method of Ship Borne Early Warning Helicopter
}

\author{
Jianguo Wang, Qun E, Jinzhu Meng, Keming Yao, and Wan Xinlong \\ Dept. of Underwater Weaponry and Chemical Defence, Dalian Naval Academy, Dalian 116018, \\ China \\ wangjianguo@163.com
}

Keywords: Ship borne early warning helicopter; Position allocation; Disposition requirements.

\begin{abstract}
The ship borne air early warning(AEW) helicopter has a good character of the good maneuvering, widely-used range, and could carry on the frigate formation, it is the effective supplement of the fixed-wing AEW aircraft. According to the characteristics of the application of the ship borne early warning helicopter, the disposition requirements and disposition methods are given, including the distance configuration model, the bearing configuration model and the height configuration model. The research results can provide a good basis for the operational use and command of the ship borne early warning helicopter.
\end{abstract}

\section{Introduction}

It is a new innovation in the field of airborne early warning using the helicopter to take the airborne early warning mission. Compared to the fixed wing early warning aircraft, the helicopter has more maneuverability and widely area using, some of the small sea fleet consisting of a cruiser, or even a destroyer can be equipped, and is a effective supplement to the fixed wing early warning aircraft[1]. The effective cooperation of the ship borne early warning helicopter with the unmanned aerial vehicle, fixed wing early warning aircraft, and the ship borne detection equipment will form a deep and solid defense system. allocation is one of the most important factors of need to be considered for the ship borne AEW helicopter combat using $[2,3,4]$, and the the allocation result is reasonable or not,will affect the combat effectiveness of ship borne AEW helicopters[4].The helicopter configuration principles, requirements and methods of in-depth study, in order to provide a useful reference for the ship borne AEW helicopters location.

\section{Disposition Principles of Shipboard Early Warning Helicopter}

Cooperative combat between the ship formation and the shipboard helicopter is the Cooperative of the formation inner. In order to detect the target of low altitude and make the formation have more time to react to the air defense, and improve the air defense efficiency of the formation, we must study the operational principle of the ship borne early warning helicopter based on the characteristics of the target, the warning helicopter and the formation, to make the limited defense resources to play the biggest role in the air defense.

Centralized control, Unified use. In different stages of sea battles, ship borne AEW helicopters carry out many tasks, the contradiction between task demand and the number of force is very prominent. Only the implementation of centralized and unified command, it could trade-off the primary and secondary from the global, and application the limited strength to the main direction and important season of the battle, and integrated air defense, attack at sea and different operational needs.

Focus deployment, Optimize configuration. Based on the direction of the threat, the formation should deployment the in accordance with the focus, taking into account the general, high and low collocation, integrated configuration of the principle of the ship borne warning helicopters to focus on the deployment, strengthen the main combat direction of the early warning troops to establish a complete warning command system. For ship borne AEW helicopters hover a short time and other 
issues, strengthen the organization, planning, establishing reasonable handover mechanism. Under the premise of ensuring the safety of the ship borne early warning helicopter, the active airspace should be as far as possible, and the long side of the patrol line should be perpendicular to the main attack direction.

Careful coordination, strengthen support. Ship borne warning helicopter to take on the duty of the empty alert, with the surface ship formation and aviation and other related forces of combat coordination will run through the battle, the battle of the whole process. It is responsible for the operational tasks such as over the line of sight guidance and information relay. Therefore, it is necessary to cooperate with the ship borne early warning helicopter. As the command and control center of the airborne tactical information, the ship borne early warning helicopter will be the main target of the enemy air attack, and the possibility of enemy electronic interference, so should strengthen its air cover and electronic support and other security activities.

\section{Disposition Requirements of Shipboard Early Warning Helicopter}

The airspace configuration of the ship borne early warning helicopter should meet the needs of the early warning and detection of the air target, meet the needs of the covert operations of the action, and at the same time, it must ensure the security of the alert helicopter. Therefore, the allocation of early warning airspace requirements are as follows:(1) It may be disposition as far as possible in the direction of the aircraft and missiles.(2) The space allocation should be as far as possible to achieve a greater alert depth. When conditions permit, it should as far as possible before the configuration, so as to provide sufficient reaction time for warship formation, tissue formation to air combat, or for air cover fighter against the enemy attacking targets implement reliable interception provide required to discover distance.(3) Space allocation should be based on the surface to air radar of the formation. It should ensure the link of the detection range of AEW helicopter and the detection range of the surface to air radar detection range;(4) It should guarantee the safety of the ship borne warning helicopter. Early warning helicopter defense capability is weak, and it must be configured on the outside of the range of the enemy (shore) air defense weapons fire. when the AEW helicopters are likely to be the enemy fighter threats, it should be configured to my fleet Antiaircraft Firepower to cover the range, if possible, the fighter should be organized the implementation of air cover.

\section{Disposition Method}

In the implementation of early warning tasks, ship borne AEW helicopters usually go ahead in threat direction before a certain distance to search and reported the situation to the Fleet Command. The AEW helicopter location is an important tactical elements, which the aircraft carrier fleet air defense combat application must determine, it includes the preceding distance, orientation and height model of the helicopter.

Anterior distance model.The anterior distance of the ship borne AEW helicopters don't only have something to do with the helicopters performance, task requirements and helicopters number, but is also related to the attack target speed, missiles range and other factors.

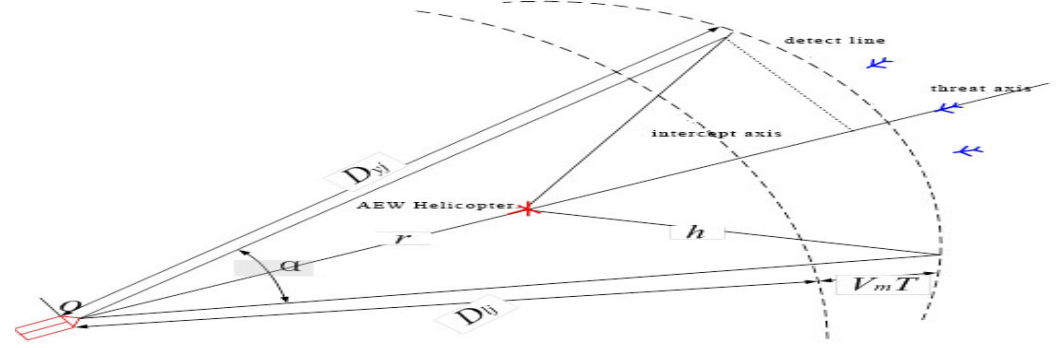

Fig. 1 AEW helicopter anterior disposition diagram

As shown in Figure1, the hypothesis in the fleet anti air combat, the squadron commander judge struck the area of enemy aircraft group is an aircraft carrier as the center of the fan, the sector of the central angle known as the carrier of the threat sector angle, denoted by $\alpha$, fan-shaped angle bisector 
is the threat axis. Warning aircraft hypothesis is configured in the threat axis distance fleet position, the detection range should be large enough to make the air interceptors can have enough time from the aircraft carrier take-off and arrive at threat aircraft intercept before being intercepted. If the detection radius of the ship borne early warning Helicopter Radar is and can cover the range of 360 degrees. From the geometric relations of the graph:

$$
\begin{aligned}
& D_{y j}=D_{l j}+V_{m} T \\
& T=T_{t x}+T_{j c}+T_{z b}+T_{j f x}+T_{g j}+T_{d f x}
\end{aligned}
$$

Where, $D_{y j}$-Warning distance of formation; $D_{l j}$ - Intercept range of formation; $V_{m}$ - The speed of the enemy air rain targets; $T_{t x}$-The time used by the carrier to find the target and return the target information to the carrier; $T_{j c}$ - The time of the anti air combat commander to judge the situation and operational decision; $T_{z b}$-The time of the aircraft from the command to take off the preparation; $T_{j f x}$ - The time of the aircraft from takeoff to can intercept flight on the enemy; $T_{g j}$ - The time of the flight attack the enemy aircraft; $T_{d f x}$-The time of the air-to-air missile from launch to hit the enemy at maximum range.

The Anterior distance of the AEW helicopter can be obtained from the equation (1) and (2):

$$
r=D_{y j} \cos (\alpha / 2)-\sqrt{h^{2}-D_{y j}^{2} \sin ^{2}(\alpha / 2)}
$$

Where, $h$-detect radius of AEW helicopter; $\alpha$-The angle of the threat fan

From the equation (3), in the processing of each perform early warning task, the anterior distance of the AEW helicopters depends on a number of different factors. These factors can be broadly divided into three categories, the early warning of the helicopter itself factors, the enemy and our factors. AEW helicopter factor is its ability to detect; enemy factors is a target enemy incoming velocity and threat sector angle, enemy targets struck speed faster and faster on the performance of our early warning requirements of the higher; our factor is refers to the communication time, command control time and fighter ready time and other factors.

Azimuth disposition model.In actual combat, the ship borne helicopter is not fixed on the threat axis on a certain point, but to do a round trip flight patrol on the vertical axis of the threat axis, which involves the deployment of a warning helicopter relative to the threat axis.

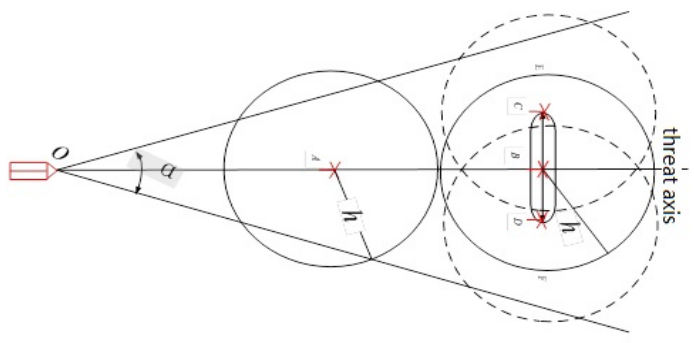

Fig. 2 AEW helicopter azimuth disposition diagram

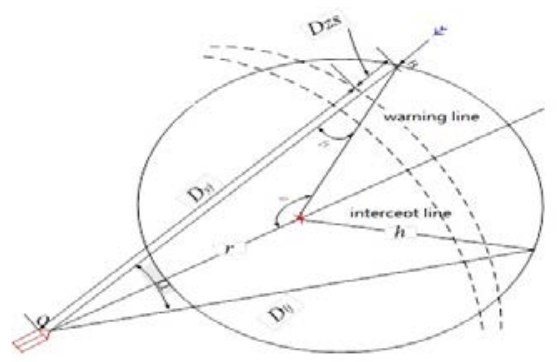

Fig. 3 AEW helicopter disposiiton diagram

As shown in Figure 2, when the threat fan angle is fixed, the distance between the helicopter and the aircraft carrier formation reference point is close (such as point A in the figure 2), helicopter surveillance detection radius $h$ is large enough to covering the entire threat sector. When the distance is far away (as shown in the B point of the picture), a certain detection blind area will appear on both sides of the probe. At this point AEW helicopter in vertical in patrol airspace threat axis of "ring" or "infinity" shaped patrol, to expand the search sector widely.

As shown in the Figure 3, when enemy planes fly along a fixed course reference point " $O$ ", and the radar of AEW contact with the enemy aircraft in point $\mathrm{B}$, it can be seen from the figure 3 , in order to effective detection of target, it must satisfy the conditions as follows:

$$
L_{o B} \geq D_{y j}+D_{z s}
$$


Where, ${ }^{L_{o B}}$ is the distance between 0 and B, $D_{z s}$ is the Search depth of the AEW helicopter, which refers to the minimum distance between the radar and the target for the first time in contact with the target to correct identification and tracking of the target.

If ship borne AEW helicopters from the first contact with the target to can stable tracking time is 30 seconds, target penetration speed is 900 kilometers / hour, then $D_{z s}=7.5 \mathrm{~km}$.

If $L_{\mathrm{oB}}=D_{y j}+D_{z s}$, Then the corresponding angle $\alpha$ is the maximum warning sector angle which the AEW helicopter can provide. when the angle the enemy penetration is larger than $\alpha_{\max }$, it will appear leakage alarm. In order to ensure early warning fan, it can achieve through helicopter's maneuver along the route which vertical to threat axis direction.

If the helicopter's detection distance to the enemy aircraft which RSC is $1 \mathrm{~m} 2$ is about 120 kilometers. When the air patrol fighter configuration $200 \mathrm{~km}$ distance, for the penetration rate for 900 kilometers / hour, anti-ship missile with a range of $220 \mathrm{~km}$ of the enemy, the corresponding warning distance ${ }^{D_{y j}}$ is 248 kilometers, and ${ }^{L_{o B}}$ is $255.5 \mathrm{~km}$.

As shown in Figure 3, the largest sector of the corresponding early warning angle can be determined by the following formula:

$\alpha_{\max }=2 \arccos \left(\frac{l_{O B}^{2}+r^{2}-h^{2}}{2 l_{O B} \cdot r}\right)$

Height disposition model. Assuming $\mathrm{H}$ is the cruise altitude which the AEW fly in the station, $h_{d}$ is the enemy target altitude. The detection range of the ship borne early warning helicopter is based on the geometry of the radar target:

$D_{t}=4.12\left(\sqrt{H}+\sqrt{h_{d}}\right)$

According to the AEW helicopter's detect distance ${ }^{D_{t}}$ and the enemy target's height $\left({ }^{h_{d}}\right)$, the minimum cruising altitude(H) of the AEW helicopter can be determined:

$H=\left(D_{t} / 4.12-\sqrt{h_{d}}\right)^{2}$

Where, ${ }_{t}$ Unit is $\mathrm{km}$, and $\mathrm{H} 、 h_{d}$ Unit is $\mathrm{m}$.

\section{Conclusion}

According to the technical and tactical characteristics of ship borne AEW helicopters, This paper summed up the principle of ship borne AEW helicopters combat use; and on this basis, it do some research on the ship borne AEW helicopters location method. Based on the allocation principle, it proposes the disposition model of distance, orientation and height. However, in modern warfare, ship borne AEW helicopters location is related to the sea weather, electromagnetic environment effects, and these factors make the allocation method more complicated. So the commander must take full consideration the real battlefield in order to policy decision reasonable ship borne AEW helicopters location.

\section{Acknowledgements}

This paper is funded by the three period of dalian naval academy 2110, also fund by the research and development of dalian naval academy.

\section{References}

[1] J.L.Guo, Z.B. Wang, P.H. Mao. Ship Electronic Engineering, 2012,32(6): 33-36

[2] J.L. Guo, Z.B.Wang, Z.H.Chang. Command Control \& Simulation, 2012,14(8): 34-38

[3] A.S.Tian, C.Y.Yin, J.L.Guo. Command Control \& Simulation, 2014,36(5): 32-34

[4] C.R.Piao, Z.H.Shen. Computer Simulation, 2013,30(2): 106-111. 